\title{
Kazimierz Krupa
}

Uniwersytet Rzeszowski

Wydział Ekonomii

e-mail: kwkrupa@ur.edu.pl

\section{Wybrane spin out Uniwersytetu Otago (zarys problematyki)}

Kody JEL: I23, O31, O33, O34

Słowa kluczowe: start-up, spin out, zarządzanie

Streszczenie. Uniwersytet Otago jest jednym z ważnych liderów promujących komercyjne wykorzystanie IP własnych pracowników naukowych. Buduje się w nim również inspirujące powiązania badawcze z sektorem prywatnym. Realizują je trzy wyspecjalizowane podmioty: Centrum Badań i Rozwoju, Otago Innovation Ltd., Centrum Innowacji Uniwersytetu Otago. Centrum Innowacji Uniwersytetu Otago (CIUO) jest ośrodkiem działającym na styku badań i biznesu, łącząc spin out Uniwersytetu Otago oraz firmy start-up z innymi podmiotami gospodarczymi, również często należącymi do MSP. W rezultacie CIUO od wielu lat skutecznie ułatwia implementację rezultatów kreatywnych technologii dostosowując je do zasad rynkowej komercjalizacji, dziś już zazwyczaj globalnej.

\section{Wprowadzenie}

Uniwersytet Otago w 2001 roku rozpoczął realizację projektu badawczego, którego strategicznym celem było zbadania realnych rezultatów zarządzania i ocena zmian organizacyjnych w 11 różnych podmiotach gospodarczych i społecznych w Dunedin. Tematy analizowane w ramach projektu to: historia życia każdej badanej organizacji, wpływ środowiska zewnętrznego, wewnętrzna dynamika, szanse i wyzwania oraz czynniki sukce- 
su organizacji. Celem aplikacyjnym naukowców realizowanym w tym projekcie było umożliwienie badanym organizacjom prezentacji własnych historii rozwoju i uzyskanego sukcesu lub porażki w taki sposób, aby można było się uczyć z tych doświadczeń. Rezultaty kompletnych obszernych panelowych badań zaprezentowano w monografii Structures and Strategies: a narrative analysis of eleven community organisations in Otago wydanej w Uniwersytecie Otago w 2003 roku.

Uniwersytet Otago utworzył również kompleksowy departament innowacyjności oparty na kreatywności własnych pracowników naukowych, który składa się z trzech odrębnych jednostek, zajmujących się promowaniem wynalazków, ich przygotowaniem do potrzeb rynkowych oraz zarządzaniem IP. Zasadniczą jednostką w tym departamencie jest Centrum Innowacji Uniwersytetu Otago, w którym funkcjonują kreatywne spin out oraz start-upy należące do nowoczesnych przedstawicieli sektora MSP. W efekcie uniwersytet ten od wielu lat skutecznie ułatwia dostosowanie rezultatów kreatywnych technologii do zasad rynkowej komercjalizacji. Głównym celem artykułu jest prezentacja wybranych informacji na temat dwóch spin out Uniwersytetu Otago, czyli Photonic Innovations Ltd i PowerHouse Ventures. Te MSP być może będą akceleratorem podobnych rozwiązań w naszym kraju.

\section{Firma Photonic Innovations Ltd. - wstępna charakterystyka funkcjonowania}

Firma Photonic Innovations Ltd. (PIL) jest przedstawicielem sektora MSP i jednocześnie spin out Uniwersytetu Otago, a jego specjalnością jest dostarczanie nowej generacji produktów wykorzystywanych do detekcji szkodliwych dla zdrowia gazów. Bardzo nowoczesne, w pełni zautomatyzowane produkty oraz rozwiązania firmy Photonic Innovation Ltd. monitorują i wykrywają zagrożenie środowiska, dotyczące głównie gazów palnych, gazów toksycznych i oceny powietrza o niewystarczającej dostępności tlenu. Bezpośrednio od powstania w 2005 roku, firma ta współpracuje z klientami, począwszy od małych przedsiębiorstw do instytucji rządowych i tworzy rozwiązania do zdalnej detekcji gazów, które znajdują zainteresowanie wśród coraz większej liczby klientów.

PIL obecnie koncentruje się na zaspokajaniu potrzeb podmiotów z kilku wybranych branż, głównie:

- petrochemicznej,

- gazowej,

- spożywczej,

- magazynowej, 
- konsumpcyjnej.

CEO Photonic Innovations Ltd. potwierdza, że ich technologia jest nowoczesna i uniwersalna, wykorzystuje IP Uniwersytetu Otago oraz może być stosowana w wielu obszarach. Pracownicy merytoryczni PIL to najlepsze umysły nauki i biznesu w Nowej Zelandii, są wspierani przez zespół naukowy Centrum Jack Dodd Quantum Technologii Uniwersytetu Otago.

Tabela 1

Partnerzy naukowi Photonic Innovations Ltd.

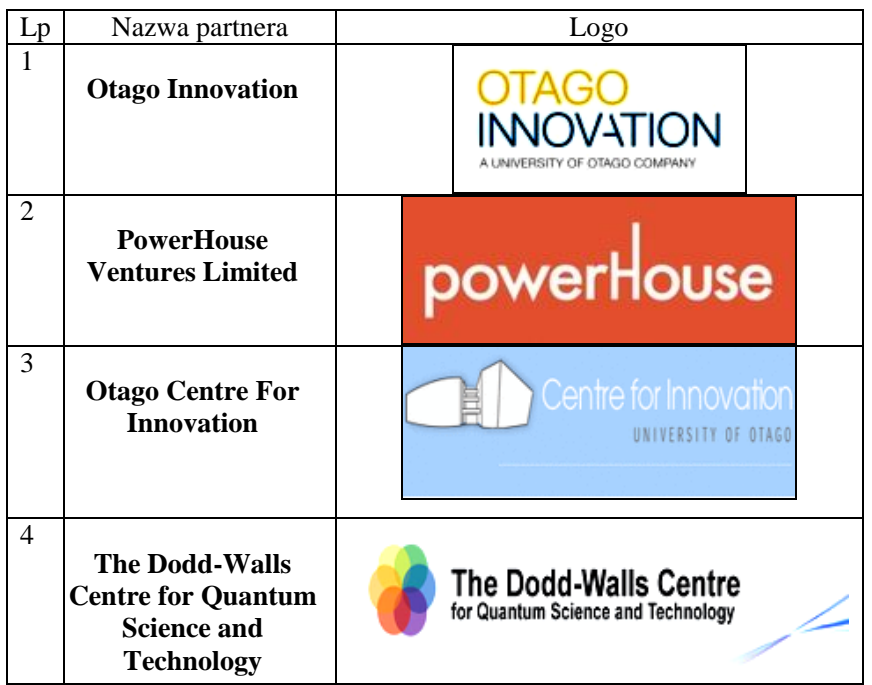

Źródło: opracowanie własne.

Kierownictwo PIL ma świadomość, że istnieje wiele środowisk pracy, w których stężenie gazów występujące w pomieszczeniach zamkniętych jest kontrolowane przez odpowiednie organy bezpieczeństwa i w związku z tym, odpowiedzialni pracodawcy ocenianych podmiotów zorganizowanych mają prawny obowiązek reagować na zalecenia tych instytucji i zapewniać bezpieczne środowisko pracy dla pracowników. Zaniechanie badania środowiska pracy może mieć dramatyczne skutki, pracownik może stracić przytomność w ciągu kilku sekund oddychania zanieczyszczonym powietrzem, co często doprowadza w rezultacie do śmierci w ciągu kilku minut. Biorąc pod uwagę nasilony charakter zanieczyszczenia środowiska naturalnego i pracy, rośnie zapotrzebowanie na stały monitoring powietrza w obszarze roboczym, które powinno być przetestowana przed wejściem pracowników na stanowiska robocze oraz stale monitorowana, gdy są już one zajęte. Wymaga to 
dostępności oraz stałego utrzymania poprawności działania urządzeń bezpieczeństwa.

Te determinanty powodują konieczność realizacji istotnych inwestycji u większości pracodawców. Dotyczy to również ogniw elektrochemicznych stosowanych w typowych detektorach. Wymagają one bowiem regularnej kontroli kalibracji oraz, z mocy prawa, wykonania nowej kontrolnej kalibracji co najmniej dwa razy w roku. Taka potrzeba ciągłej obsługi detektorów gazu jest istotnym obciążeniem dla pracodawców i logistycznie ogranicza dostępność kalibrowanych urządzeń wówczas, gdy są one w certyfikowaniu.

Firma Photonic Innovations Ltd. dostarcza ,inteligentne” wykrywacze gazów, które są nie tylko najbardziej zaawansowane technologicznie i najtańsze z produktów dostępnych na rynku, ale także nie wymagają ciągłego serwisowania. Photonic Innovations poza oferowaniem wyrafinowanych technologicznie produktów świadczy również usługi w zakresie detekcji gazów stosowanych w branżach: a) używających amoniaku jako czynnika chłodzącego; b) żywienia zbiorowego; c) przemysłowych; d) oczyszczania ścieków.

Firma Photonic Innovations Ltd. implementując kolejne innowacyjne rozwiązania i wdrażając kreatywne wynalazki współpracuje z wieloma centrami badawczymi Uniwersytetu Otago oraz podmiotami gospodarczymi. Wykaz wybranych partnerów naukowych firmy Photonic Innovations Ltd. zaprezentowano w tabeli 1, a analiza danych wskazuje, że przedstawione współpracujące ośrodki należą do Uniwersytetu Otago i są centrami kreowania oraz wykorzystania innowacyjnych wynalazków. Uzasadnione wydaje się więc, że Photonic Innovations Ltd. w roku 2014 została uznana przez Deloitte jako Fast50 'Rising Star - One to Watch' jako najlepsza firma na wyspie południowej.

\section{PowerHouse Ventures Ltd. - wybrane informacje}

Firma spin out PowerHouse Ventures Ltd. (PHL) jest również przedstawicielem sektora MSP. Obecnie opracowano w niej skuteczną i oryginalną metodologię systematycznej komercjalizacji własności intelektualnej, obejmującej następujące cztery główne etapy:

1. Projekcja komercjalizacji IP.

2. Kształtowanie określonych technologii w celu dopasowania wyrobu do potrzeb rynku.

3. Przygotowanie przedsięwzięcia do uruchomienia inwestycji.

4. Kierowanie testowaniem założeń potwierdzających stan gotowości przedsiębiorstwa do dalszych inwestycji. 
Etapy te to sedno metodologii PowerHouse, gwarantującej sukces inwestycji w taki wynalazek, który jest oceniany jako mający największe prawdopodobieństwo stania się np. technologią wysokiej wartości, również rynkowej.

PowerHouse Ventures Ltd. w ramach doradztwa biznesowego często proponuje inkubację firm, zapewniając kapitał, wiedzę, budowanie sieci biznesowej firmy, rekrutację kadry i mentorskie wsparcie. W PHL opracowano oryginalną i skuteczną metodologię kompletnego programu inkubacji, która jako proces obejmuje badania oraz rozwój komercyjnej firmy. Firma PowerHouse wykorzystuje własną procedurę rozwoju przedsięwzięcia. Proces ten oparty jest na opracowanych i przetestowanych w praktyce rynkowej zaawansowanych narzędziach oceniających potencjał rynkowy konkretnego rozwiązania, a szczególnie ustalenie czy jest to specjalna okazja biznesowa. Ocenę technologii przeprowadza się według kryterium szansy rynkowej, stosując standardowe i autorskie narzędzia oceny. Po uzyskaniu oceny z metody standardowej, w dalszej kolejności testuje się dany IP. Ta część procesu polega $\mathrm{w}$ pierwszej kolejności na identyfikacji potencjalnych grup klientów. Następnie przeprowadza się rozmowy typu jeden na jeden, aby zrozumieć, jak klienci oceniają rozwiązanie, a gdy ich potrzeby są określone, odpowiednie możliwości techniczne mogą być kolejno rozwijane. Uzyskane materiały empiryczne pozwalają jasno zdefiniować parametry, jakie przedsiębiorca lub badacz musi osiągnąć, aby mieć realny produkt z sukcesem rynkowym.

Jest również bardzo ważne dla procesu badawczego to, że ta działalność stanowi cenny wgląd w rynek w rezultacie prawidłowego sprzężenia zwrotnego, a czasem spill over. W szczególności, specyfikacje klientów dostarczają naukowcom wymierne cele dla ich dalszej pracy. A przedsiębiorcy, zyskują ważne informacje o walidacji rynkowej ich idei.

Taka koncepcja pracy PowerHouse Ventures Ltd. pozwala na swobodę wyszukiwania i rozwijania strategii kreacji nowych pomysłów, prowadzoną przez specjalistów IP. Cały proces poszukiwania innowacyjnych pomysłów i rozwiązań dających sukces rynkowy, np. inkubacji IP, stanowi kluczowy element oceny określonej technologii i jest podstawą budowy mapy drogowej jej rozwoju. Składa się on z:

1. Procedury inkubacji technologii. Jest to kolejne przedsięwzięcie realizowane według autorskiej metody PowerHouse. Najważniejszym zadaniem jest prowadzenie właściwej procedury inkubacji technologii zgodnie z określonymi potrzebami przyszłych klientów. Celem tego etapu jest znalezienie odpowiedniego klienta produktu, pozyskanie funduszy pre-finansowych ze specjalnych środków Otago, a następnie dostarczenie produktu w ręce klienta. 
2. Wyboru mentora przemysłu i doraźnego CEO. Podczas inkubacji konkretnego innowacyjnego rozwiązania lub patentu kolejnym etapem metody jest wybór mentora przemysłu związanego z rynkiem albo z doświadczeniem pracy w przemyśle. Ktoś taki może pomagać potwierdzać, że proponowane rozwiązanie jest znaczącą okazją rynkową i może ułatwiać uzyskanie możliwości inwestycyjnych. Doraźny CEO jest także identyfikowany, zwykle z technicznym profilem i zazwyczaj jest odpowiedni dla objaśniania wymogów klientów. Coraz częściej jest także compliance officer. Zwykle spełnia on również rolę łącznika $\mathrm{z}$ grupami badawczymi.

3. Serwisu inkubatorowego. Serwis inkubatorowy to część procesu, który sprawia, że jest siła unikatowa wynikająca z połączenia najlepszych cech stargetowej inwestycji z inicjatywami biznesowej inkubacji. Inkubator Uniwersytetu Otago skutecznie, co jest wielokrotnie potwierdzane w biznesowej praktyce, umożliwia każdej firmie start-up i spin off dzielenie się wiedzą, korzyściami z ekonomii skali oraz uzyskanie dostępu do wielokrotnego wsparcia finansowego. Najważniejszym więc celem serwisu inkubatorowego jest zapewnienie dla IP realnego wsparcia, które w profesjonalny sposób umożliwi bezpieczne przejście innowacyjnej idei technologicznej w live cycle od pomysłu do biznesowej i rynkowej rzeczywistości. Wsparcie inkubacji obejmuje głównie:

- dostęp do kapitału na rozwój firmy,

- zdobycie dogłębnej wiedzy na temat rynku,

- zapewnienie pomieszczeń do realizacji produkcji.

4. Funduszy Venture capital wykorzystanych w procesie inkubacji. PowerHouse Ltd. promuje finansowo pomysły:

- dzięki którym przedsiębiorstwa będą zdolne do pracy w jasno określonej niszy i na szybko rozwijającym się rynku,

- dysponujące potencjałem, dzięki któremu przedsiębiorstwo ma szansę stać się liderem na rynku,

- opatentowane lub mające inne silne bariery zabezpieczające przed wejściem na rynek,

- rokujące rentowność,

- oraz firmy, które „pasują” do przyjętego w strategii Otago profilu ryzyka/nagrody.

PHL preferuje możliwości związane $\mathrm{z}$ innowacyjną technologią, w szczególności powstałe na podstawie osiągnięć nauki lub technologii, pochodzące z uczelni regionu i czołowych instytutów badawczych. Poszukuje ono również innowacji technologicznych wśród utalentowanych przedsiębiorców. Obszary szczególnego zainteresowania PowerHouse Ventures Ltd. to: 
- inżynieria i czysta technologia,

- biotechnologia i nauki rolne,

- urządzenia medyczne,

- żywność,

- ICT, software.

PowerHouse Ventures Ltd. analizując innowacyjne rozwiązania i wdrażając wynalazki ma kontakty biznesowe $\mathrm{z}$ dwunastoma podmiotami gospodarczymi. Wszystkie współpracujące z PowerHouse organizacje gospodarcze należą do high technology oraz są centrami kreowania i wykorzystania innowacyjnych wynalazków.

\section{Podsumowanie}

Skuteczne wprowadzanie innowacji produktowych oraz organizacyjnych jest aktualnie już uważane za zasadnicze źródło długoterminowej przewagi konkurencyjnej. W procesie tym zwykle bardzo aktywne uczestniczą firmy MSP, do których należą także spin out oraz spin off. Ostatnio jednak często odchodzi się od tradycyjnej definicji innowacji i cała koncentracja aktywności skupia się na aspektach innowacyjności, w rezultacie zwraca się szczególną uwagę na innowacje rozwiązań organizacyjnych lub w obszarze ochrony Kapitału Intelektualnego, co ma stargetowe znaczenie dla ośrodków badawczych uniwersytetów i dla poprawy oceny finansowej firm komercyjnych, wykorzystujących kreatywne rezultaty badań naukowych (np. spin out i spin off).

Wiele uniwersytetów oraz ośrodków badawczych tworzy specjalne procedury i uruchamia zespoły zajmujące się komercjalizacją ich dorobku naukowego. Uniwersytet Otago, jako jeden z najstarszych i największych powołał w tym celu kilkanaście instytucji, których zadaniem jest wykazanie praktycznej zdolności do wprowadzania odpowiedniej polityki i strategii, ukierunkowanych na innowacyjność i jej wykorzystanie. Uniwersytet jest również inicjatorem uruchomienia centrów start-upowych. Skuteczne rozwiązania Otago mogą być dobrym przykładem oraz również inspiracją dla zainteresowanych przedsiębiorstw MSP i szansą na uzyskanie przez nie efektu spill over.

\section{Bibliografia}

Aimers, J., Walker, P. (2003). Structures and Strategies: a narrative analysis of eleven community organisations in Otago. Otago: Department of Community and Family Studies, University of Otago. Monograph series, December.

Boon, B., Farnsworth, J. (2015). Social exclusion and poverty: Translating social capital into accessible resources. Dunedin: Social Policy \& Administration. 
Boon, B., Jones D., Curnow, B. (2009). Out of the Blue: The dark side of creative enterprise. Culture and Organisation, 15 (3-4), 361-377.

Bould, N. (2010). Sustainable Design Education in New Zealand (2010). Department of Geography Post-Graduate Symposium, Department of Geography. Dunedin: University of Otago.

Bould, N. (2009). Sustainable Design Education: A journey towards environmental activism. Paper presented at the JENESYS Program 2008/2009, Tokyo, Japan.

Bould, N. (2009b). Sustainable Design Education in New Zealand. International Association of Societies of Design Research [IASDR] 2009 Conference, Seoul, Korea.

Farnsworth, J., Boon, B. (2010). Analysing group dynamics within the focus group. Qualitative Research, 10 (5), 605-624. DOI: 10.1177/1468794110375223.

Fox, A. (2015). Neuroscience and the reaction against postmodernist critical theory. Verbal presentation at the what [in the World] Was Postmodernism? SYMPOSIUM. Dunedin, New Zealand.

Fox, A. (2008). The ship of dreams: Masculinity in contemporary New Zealand fiction. Dunedin, New Zealand: Otago University Press, 230p.

Harding, J.E. (2012). Divine knowledge in the book of Job and 4QInstruction. W: D. Burns, J.W. Rogerson (red.). Far from minimal: Celebrating the work and influence of Philip R. Davies (173-192). London: T \& T Clark.

Hippel, E. (1995). The Sources of Innovation. New York: Oxford University Press.

Jacob, E., Johnson, H. (red.). (2014). Asia in New Zealand Lives. Spec. issue of the New Zealand Journal of Asian Studies 16.2.

Jacob, E. (red.). (2008). Representing Asia, Remaking New Zealand in Contemporary New Zealand Culture. Spec. issue of New Zealand Journal of Asian Studies, 10 (1).

Scott, J.H. (2015). Transactions and Proceedings of the New Zealand Institute. Contribution to the Osteology of the Aborigines of New Zealand and the Chatham Islands, 26 (1-64, $24 \mathrm{p}$.

Shogimen, T., Spencer, V.A. (red.). (2014). Visions of peace: Asia and the West. Farnham, UK: Ashgate.

Shogimen, T. (2014). Genron Yokuatsu: Yanaihara Jiken no Kozu (The suppression of speech: Mapping the Yanaihara Incident). Tokyo: Chuo Koron Shinsha.

\section{Chosen Spin out University of Otago (Outline of Issues)}

Keywords: start-up, spin out, management

Summary. The Otago University is one of own researchers valid for leaders promoting the commercial IP application. He is building also inspiring research connections with the private sector. To facilitate this process appointed to life three entities. These are: Innovation Centre of the University of Otago, Centre for Research and Development, Otago Innovation Ltd. Centre of the Innovation of the Otago University (CIUO), he is a centre acting on the joint of examinations and the business, is linking spin-out of the Otago University and the company start-up with other business entities and offices of the University. As a result from the row of years effectively he to principles of the market commercialization, today is already usually facilitating the implementation of results of creative technologies global.

Translated by Pavlo Skotnyy

\section{Cytowanie}

Krupa, K. (2016). Wybrane spin out Uniwersytetu Otago (zarys problematyki). Marketing i Zarządzanie, 2 (43), 83-90. 